\title{
ENZYMES AND BLOOD CLOTTING. I. TRYPSIN AS AN ACCESSORY FACTOR *
}

\author{
By JOHN H. FERGUSON, ELLA GRAY WILSON, SOTIRIOS G. IATRIDIS, $\dagger$ \\ HERMAN A. RIERSON AND BETTY R. JOHNSTON
}

(From the Department of Physiology, University of North Carolina School of Medicine, Chapel Hill, N. C.)

(Submitted for publication June 10, 1960; accepted August 17, 1960)

There is considerable literature, cited (1), on various agents which, besides having proteolytic activity, can influence blood clotting. Some of these are crystalline enzymes, such as trypsin and papain. Others are crude materials, in which the active principle has yet to be identified. The ways in which clotting is affected by these diverse agents have been studied to varying extents. There have also been relatively recent discoveries of a number of natural "accessory" factors, participating in the thromboplastin- and thrombin-forming reactions. These will be referred to by the Roman numeral designations of the International Committee on Blood Clotting factors (2), or by one or two of the common abbreviated synonyms, as follows: V (AcG), VII [SPCA, or "proconvertin" (ProC.) in the strict sense], VIII (AHF), IX (PTC, or Christmas factor), X (Stuart-? Prower), PTA (plasma thromboplastin antecedent), Hag (Hageman factor). The time is especially ripe to work out what relationships may exist between these accessory factors and the "enzymes" in question.

Illustrating some of the agents which will be included in the present series of investigations, Table I shows a heterogenous group of additives all of which can clearly accelerate the clotting of whole blood (in silicone). The following methods of study will be followed. First, the agents will be added to a variety of routine nonspecific clotting test systems. Second, they will be tested in one-stage (3) and two-stage (4) systems, which have been devised for the specific assay of individual clotting factors. By testing in systems deficient in just one factor at a time, it is possible to

\footnotetext{
* Aided by Grant (H-1510, $\mathrm{C}_{7}$ ) from the NIH Division of Research Grants and Fellowships, Besthesda, Md.

$\dagger$ Appointment supported by the International Cooperation Administration under the Visiting Research Scientist's Program administered by the National Academy of Science of the United States.
}

bring out relationships between the test agents and the natural clotting factors. Finally, the indications afforded by the preceding results will be followed up with special tests in order to define more precisely the modes of action of each agent studied. Where possible, effects of "combining" each clotting factor with the enzyme preparation will be tested on appropriate clotting systems.

In the first paper of the series, these considerations will be illustrated by an experimental analysis of the effects of trypsin. The ability of trypsin to accelerate blood clotting was discovered by Douglas and Colebrook (5) in 1916; in 1937, Eagle and Harris (6) gave evidence for its role in the activation of prothrombin to thrombin. We (1) have contributed many publications in the past 20 years (1939 to 1959) to explain the action of trypsin in the thrombin-forming system as that of a "thromboplastic enzyme" (7) (see Discussion), working in conjunction with Ca ions and a prothromboplastic lipid (4), which can be provided by platelets, cephalin and so forth. Many of our earlier experiments, however, preceded the era of modern knowledge of the natural accessory factors and it is particularly in relationships to these that the present data bring out some important new concepts.

\section{FOREWORD ON CLOTTING TEST METHODS}

Although most readers will be familiar with the routine clotting test procedures, with the possible exception of some of the "specific" methods, there are many facts and ideas implicit in their interpretation which are not widely appreciated.

Nonspecific tests. Since blood does not clot while normally circulating in vivo, any clotting must be the result of nonphysiological circumstances. Many factors are now known to participate in the reactions of blood coagulation. We are, for the most part, still far from the goal of identifying and quantitating them biochemically. Almost all progress in this field relies upon tests of "activities," which determine clotting times in vari- 
ous multicomponent test systems, affected by numerous variables.

In clotting tests performed on shed (e.g., arm-vein) blood, much depends upon the technical details of handling. Avoidance of tissue contact, for instance, is generally emphasized. In the "spontaneous" clotting of such whole blood, in vitro at body $\left(37^{\circ} \mathrm{C}\right)$ temperature, the chief variable is the contact surface(s). It is now a common routine to test in both glass and silicone. There is good recent evidence $(8,9)$ that the PTA and Hageman factors interact in the presence of certain surfaces, e.g., glass, to form a powerful accelerator of the initial phases of blood clotting. "Surface factor" (SF) (10) or "activation product" (11) are convenient terms for this.

In plasma recalcification ( $\mathrm{PCa}$ ) tests, factors connected with the technical handling must be expected to afford opportunity for formation of this SF. Plasma is collected, with varying technical skill, by receiving blood into some anticoagulant, usually citrate or oxalate, centrifuging (another variable), storing and so forth, under various conditions of exposure to surfaces, temperature changes and the like. Traces (or more) of the formed elements, especially platelets, are not negligible contaminants. Only a few workers, including ourselves, have obtained plasmas so free from platelet material as to be incoagulable on simple recalcification (1). Our ordinary routine is to use the silicone technique, merely centrifuging the (citrated) blood in the cold $\left(4^{\circ} \mathrm{C}\right)$ for 30 minutes at $3,000 \mathrm{rpm}$, to obtain what we, hopefully, call "platelet-poor" plasma. Typically, this gives $\mathrm{PCa}$ times of 5 to 7 minutes soon after preparation, but this is reduced to 2 to 3 minutes in a few hours, especially on exposure to glass surfaces and room temperatures. Evidently, the benefits of platelet removal are partly counteracted by plasma "activation" phenomena. We probably do not know all possible activations which may occur in shed blood and plasma.

On the other hand, there are also "removals." Depending largely on storage conditions, some clotting factors are labile. There are species variations. In human blood or plasma, factor $\mathrm{V}$ (AcG) is particularly labile and factor VIII (AHF) moderately so. Freezing and thawing plasmas, or preparing them in the lyophile-dried state, are also productive of alterations. Even a trace of clotting can affect a blood sample considerably. Serum has its own problems as to clotting factor components, and so do all fractions. Sometimes plasmin (fibrinolysin) complicates the picture. The over-all practical question concerns the quantitative level of each clotting factor present and its ability to affect the results of the clotting test in question. We are very apt to take for granted the nonvariance of many factors when this is merely fortuitous under most ordinary circumstances. There is actually a dearth of accurate information on many of these technical points.

The PT (prothrombin time) test of Quick (12), is performed in our laboratories by adding to $0.1 \mathrm{ml}$ oxalated (or citrated ) plasma, $0.1 \mathrm{ml}$ of optimal strength human brain thromboplastin, and $0.1 \mathrm{ml} 0.02 \mathrm{M} \mathrm{CaCl}_{2}$, at $37^{\circ} \mathrm{C}$. Our normal human plasmas, routinely tested in glass after a few hours from the blood collection, usually yield a PT time of 11 to 12 seconds. The Quick test clotting times are so short that it is difficult to assess the significance of variations less than 1 to 2 seconds. Valuable as this test is, it can detect only relatively gross factor variations. PT's are significantly lengthened in deficiencies of factors II (prothrombin), V (AcG), VII (SPCA) and X (Stuart) but, rarely, because of very low fibrinogen $(\mathrm{I})$, or in the presence of heparin and some other inhibitors. While properly including the Quick test in the nonspecific group, it is, nevertheless, recognized for its value as a screening test for the limited group of factors mentioned above.

The PTT (partial thromboplastin time) test, developed by Langdell, Wagner and Brinkhous (13), we now perform routinely with optimal (usually 0.06 per cent) human brain (crude) cephalin (14) substituted for the thromboplastin of the PT test. The PTT test is sensitive to variations in, or additions of, V, VIII, IX, X, PTA, Hageman, and SF. Surface factor may be formed in glass or added in certain reagents (10). As with the PCa tests, and probably for the same reassons, the normal PTT controls show considerable variation. A good routine is to keep the platelet-poor plasma in an ice-bath and test as soon as possible. Of course, this is impracticable with many plasmas, especially those from clinical patients. When saved for "substrates" (see below), most of these are kept frozen-stored at $-20^{\circ} \mathrm{C}$ in siliconed or lusteroid tubes. Occasionally, we have available only lyophilized substrates, but the test results on these are regarded with considerable reserve.

Specific one-stage tests. When a substrate plasma is chosen, which is specifically deficient in the factor to be tested, prolonged clotting times will be obtained in one or more of the above nonspecific tests. If the missing factor is added to the substrate, the clotting time will be reduced, and this can be made the basis for a bioassay. Equal 0.1 (or 0.05 ) $\mathrm{ml}$ volumes of substrate plasma and the unkown are mixed and tested with the appropriate additions of calcium and thromboplastic agent. The clotting times may be compared by inspection or quantitated as activities by reference to a series of standards. Details are given in previous publications $(1,3)$. A $1: 10$ dilution of (standard) normal human plasma is conveniently regarded as 100 per cent (of normal), especially in testing unknown plasmas similarly diluted. Specific PT-type tests are set up in this way for factors II (prothrombin), V (AcG), VII (SPCA) or X (Stuart) separately, or (VII + X) together [after Owren (15)].

Similarly, the PTT-test principle is applied specifically by adding the test material to substrate plasmas respectively deficient in V, VIII (AHF), IX (PTC), X, PTA, or Hageman. Variables which are apt to be overlooked may include: 1) uncontrolled SF formation (see above) ; 2) loss of $\mathrm{V}$; 3) variation of more than one factor at a time; 4) special inhibitor problems, which are rare (16) [which may also affect PT tests and so forth (17)]. It 
must be remembered that each one of the cited clotting factors makes its own quantitative contribution to the clotting test and that all are necessary.

Truo-stage tests. The principle of the two-stage test is: first, to incubate together the factors necessary to form thrombin; and second, to follow the thrombin formation by adding successive samples of incubate to a standard test fibrinogen. Other things being equal, the more thrombin formed, the shorter the clotting time. A plot of the data yields a "prothrombin activation curve (18) affording information on both rate and yield. We always follow through the endpoint (optimum) or shortest clotting time reached, and report this together with the incubation period (opt.) needed, as well as the initial ( 0.5 or 1 minute) data. Intervening values provide little additional information. Conditions for these tests must be rigorously standardized. This is most satisfactorily achieved in the research laboratory, but, like any other special procedure, can be learned through experience. Our particular type of two-stage test is the oldest, dating back to the original discovery of prothrombin and of the roles of calcium and tissue extracts. Its special features are: 1) the use of an unvarying source of prothrombin (for each group of experiments) ; 2) a weak preparation in the incubate corresponding to perhaps 3 to 6 "Iowa" units (see below) per $\mathrm{ml}$; 3) varying rates and yields according to the activators (and/or inhibitors) being tested; 4) comparing endpoints, often by simple inspection, for the comparative series or 5) comparing with a series of empirical standards (as in any other clotting factor assay). For instance, the last feature mentioned proved very satisfactory in clinical studies on plasma prothrombin, correlating excellently with the WareSeegers (19) two-stage and with our specific one-stage (3). Last year, we presented data (4) to illustrate, in principle, how this two-stage test could be modified to quantitate any individual factor involved in thrombin formation. Just as tissue thromboplastin or cephalin (prothromboplastic phosphatide) can be selected for the various specific modifications of the one-stage, so, too, the two-stage may be similarly modified. The fundamental principle is simply that if the system is set up to be deficient in just one factor at a time, it is practicable to use it for the bioassay of that single factor. The very important advantage of our two-stage is that it permits quantitative control of all factors at the same time. This is achieved by independently assaying for each factor in all the reagents (by one-stage or two-stage methods). This kind of control is essentially new and can explain many results of earlier studies, in our own and in many other laboratories, about which we could only guess in the absence of such total factor control. In a "complete" two-stage system, that is, with a fixed (small) amount of prothrombin and optimal (or nearly so) amounts of every one of the other factors needed, thrombin formation is maximal in 2 to 3 minutes, typically. By keeping all accessory factors optimal, except the one tested, the quantitations of additions of the test factor are extremely reliable and specific. Some details of the needed rea- gents are discussed in Reference 4, and the same conference proceedings include pertinent comments of the late lamented Dr. Hans Jensen, on the technical difficulties in standardizing these test systems. The other type of twostage was developed by Smith, Warner and Brinkhous (20) and modified by Ware and Seegers (19). This may be termed the "Iowa" method, with its "Iowa (pro) thrombin units." The special feature of this method is to reach a fixed (15 second) ${ }^{1}$ endpoint (or almost), varying the dilution of the prothrombin in several steps prior to and during the activation. Total dilution $\times 1$ (or correction factor $)^{1}$ constitutes the Iowa unitage. This method obviously does not permit simultaneous quantitative control of all factors in the thrombin-forming system. Ware and Seegers (21) did use it for AcG (V) assays, according to the same principles as our new modifications (4), except for lack of quantitation of the other accessory factors. Seegers and colleagues have published an important and impressive body of work on very many aspects of prothrombin activation and so forth. We would like to point out that, in the many instances [e.g., citrate-activation (22)] in which prothrombin of high purity and very great potency is activated (or altered), the final testing for prothrombin and thrombin unitage does not tell anything about effects which could be due to trace contaminants of even the very best prothrombin preparations. Indeed the excessive amount of prothrombin itself could make it impossible to detect, by independent testing, the presence of possible trace impurities. It is very clear from many workers' experiments, that some, at least, of the accessory factors (which normally accompany prothrombin in plasma) are active in very high dilutions. We have ourselves (23) experienced the complete "spontaneous" activation (on simple standing for several months in solution in the refrigerator) of some of Seegers' prothrombins. We could only attribute this to trace contaminations with all the necessary activators (1). Moreover, Alexander (24) has obtained prothrombin, comparable in purity and potency to Seegers' preparations, in which citrate activation did not occur, until some accessory factor (e.g., proconvertin) was added. Others have similar data, so that there is currently considerable uncertainty as to exactly what factors are essential for thrombin formation. This question of trace contaminants becomes very important in trying to carry our present theme, on the role of enzymes in thrombin formation, to highly purified prothrombin (and so forth) preparations. A further word will be said on this in the Discussion.

\section{METHODS AND MATERIALS}

These are fully described, for the most part, in previous publications $(1,3)$. Test procedures, based upon the principles discussed in the Foreword, include: 1) whole blood clotting time (CT), in glass (A) or in silicone (B) ; 2) plasma recalcification clotting time (PCa) ; 3) Ca-tissue thromboplastin-plasma clotting

1 Only when the endpoint is 15 seconds is the multiplication factor 1 , otherwise a correction factor is needed. 
time (PT), after Quick, Stanley-Brown and Bancroft $(12)$; 4) Ca-cephalin-plasma clotting time (PTT), after Langdell and co-workers (13), using substrate plasmas from $a$ ) normal (N), b) hemophilic (VIII- or AHF-), c) Christmas disease (IX- or PTC-) or $d$ ) Hagemandeficient (Hag-) subjects $(25) ; 5)$ specific one-stage plasma tests for clotting factors-(VII + X), i.e., "proconvertin" in the wider sense, after Owren (15); VII (SPCA or proconvertin proper) and X (Stuart), separately assayed on appropriate patients' plasma substrates; II (prothrombin); V[AcG or (pro)accelerin] ; 6) specific two-stage tests, on eluates (containing prothrombin and so forth), activated with cephalin (instead of tissue thromboplastin) for the special purposes discussed in the Foreword $(4) ; 7$ ) other tests, as mentioned in the text. In many experiments, trypsin was tested in combination with (VII $+\mathrm{X}$ ) (see below) in order to study a "synergistic" phenomenon (26).

Substrates. A routine for human arm-vein blood collection and plasma separation is described in the Foreword; dog blood is handled similarly. Bovine blood is collected in bulk at the slaughterhouse, flowing from the neck section too freely to permit significant tissue contamination. Suitable clinical cases provide factor-deficient plasmas and fractions (1). Artificially prepared substrates (3) include: one-stage prothrombin-(ProT-) substrate; $\mathrm{V}(\mathrm{AcG})$-substrate ("aged" human plasma); VII- and X- (ProC-) substrate [Owren's (15) asbestosfiltered bovine plasma]; plasma eluates obtained with the $\mathrm{BaSO}_{4}$-citrate or $\mathrm{Al}(\mathrm{OH})_{3}$-phosphate (and dialyzed). techniques (1). B. sal., imidazole-buffered $\mathrm{NaCl} \quad(\mathrm{pH}$ 7.3) was the routine solvent and diluent.

Trypsins. Tryp. A, Worthington's, twice crystallized, salt-free, after Kunitz and Northrop (1936) ; Tryp. B, a similar commercially available preparation from the Mann Co; Tryp. C, ordinary ("1-300") commercial (N.B. Co.) trypsin. In our test systems, very small concentrations of trypsin suffice and we cannot detect any significant differences between crystalline and " $1-300$ " trypsin, except for the greater potency of the former.

Clotting factors. In advance of the distant goal of biochemical purification of individual clotting factors, we rely upon fractions meticulously tested for all factor activities which might conceivably affect their behavior in the various clotting systems in which they are used. This works out very well in actual practice. $(\mathrm{VII}+\mathrm{X})$ was a bovine serum proconvertin, fractionated (in 1955) by our earlier procedure (27), and maintained in frozen-storage at $-20^{\circ} \mathrm{C}$. It contained a trace of prothrombin, which the standard (19) two-stage assays showed to be $<5$ per cent of that in normal plasma. This was all but negligible in the $1: 10$ or $1: 50$ dilutions used for most of the special experiments. Some other special preparations will be described in appropriate sections of the text.

\section{RESULTS}

Whole blood clotting tests. Table I serves to indicate coagulant activities in a heterogeneous
TABLE I

Effects of various agents on whole blood clotting time, in silicone*

\begin{tabular}{cllc}
\hline \hline Test & \multicolumn{1}{c}{ Agent added } & Strength & $\begin{array}{c}\text { Clotting } \\
\text { time }\end{array}$ \\
\hline & & & $\min$ \\
1 & B. sal. (control) & & 24 \\
2 & Trypsin A & $20 \mu \mathrm{g}$ & 9 \\
3 & Papain & $1: 2500$ & 10.5 \\
4 & Bothropase & $1: 100$ & 7 \\
5 & Stypven & $1: 100,000$ & 3 \\
6 & Thrombin $\left(\mathrm{T}_{\mathrm{S}}\right)$ & 0.01 unit & 8.5 \\
8 & Plasmin B & 10 units & 7
\end{tabular}

* Clotting times, in minutes, at $37^{\circ} \mathrm{C}$, of $1.8 \mathrm{ml}$ arm-vein blood added to $0.2 \mathrm{ml}$ of agent in buffered ( $\mathrm{pH} \mathrm{7.3)}$ saline at the strengths stated (per $\mathrm{ml}$ of final clotting mixture).

group of agents, the elucidation of which is the project of these studies. Characterization of most of these agents will be deferred until the specific later presentations. The Tryp. $\mathrm{A}$ is relevant to the present communication and is described under Methods. The reader's curiosity as to the special "thrombin" ( $\left.\mathrm{T}_{\mathrm{S}}\right)$ may be satisfied, for the time being, by stating that this was a pool of canine plasma $\mathrm{BaSO}_{4}$-citrate $(0.2 \mathrm{M})$ eluates which had undergone complete spontaneous conversion to thrombin over several years in the deep-freeze $\left(-20^{\circ} \mathrm{C}\right)$; besides thrombic activity, this solution was rich in proteolytic activity. Results similar to those in Table I have been obtained, repeatedly, in glass as well as in silicone. Table II is a similar experiment with varying concentrations of crude trypsin (Tryp. C) tested (A) in glass, (B) in silicone. Clot-retraction and clot lysis were also followed. The former was normal $(\mathrm{N})$ in all tests. Lysis was complete $(+)$ with the $500 \mu \mathrm{g}$ per $\mathrm{ml}$ trypsin in 24 to 48 hours, and incomplete $( \pm)$ or absent $(\infty)$ in the other dilutions. Natural trypsin inhibitors in the blood undoubtedly lessen the enzyme's activity. Clot acceleration was evident even with $5 \mu \mathrm{g}$ per $\mathrm{ml}$ of the crude trypsin and was more marked with the higher enzyme concentrations. The finding of

TABLE II

Whole blood clotting time in minutes *

\begin{tabular}{|c|c|c|c|c|c|c|}
\hline Trypsin $(\mathrm{mg} / 2 \mathrm{ml})$ & 1.0 & 0.2 & 0.1 & 0.02 & 0.01 & $\mathbf{0}$ \\
\hline $\begin{array}{l}\text { (A) Glass } \\
\text { (B) Silicone } \\
\text { Clot-retract. } \\
\text { Clot lysis }\end{array}$ & $\begin{array}{c}4 \frac{1}{4} \\
\stackrel{4}{2} \\
1-2 \text { days }\end{array}$ & $\begin{array}{c}7 \frac{1}{2} \\
7 \frac{1}{2} \\
\mathrm{~N} \\
\pm 2 \text { days }\end{array}$ & $\begin{array}{l}7 \frac{3}{4} \\
9 \frac{1}{4} \\
N \\
\infty\end{array}$ & $\begin{array}{c}91 \\
11 \frac{1}{2} \\
N_{\infty}^{4}\end{array}$ & $\begin{array}{l}12 \\
14 \\
N \\
\infty\end{array}$ & $\begin{array}{c}13 \frac{3}{4} \\
20 \\
N \\
\infty\end{array}$ \\
\hline
\end{tabular}

* Additions of trypsin, $0.2 \mathrm{ml}$, to $1.8 \mathrm{ml}$ blood at $37^{\circ} \mathrm{C}$. 
TABLE III

Effects of crystalline trypsin, $(V I I+X)$ and a "combination," in routine nonspecific one-stage plasma clotting tests *

\begin{tabular}{llrrr}
\hline Test & \multicolumn{1}{c}{ Additives } & PCa & PT & PTT \\
\hline 1 & 0 (B. sal.) & 189 & 13.1 & 86.1 \\
2 & Tryp. A, 5 $\mu \mathrm{g}$ & 79.4 & 12.6 & 50.1 \\
3 & (VII + X) 1:50 & 108.1 & 12.7 & 72.7 \\
4 & Tryp. A + (VII + X) & 32.4 & 9.4 & 14.2
\end{tabular}

* Clotting times in seconds, at $37^{\circ} \mathrm{C}$.

almost the same degree of clot-acceleration in silicone as in glass, is suggestive evidence that it does not require SF (see Foreword), which is currently $(8,9,11)$ believed to depend upon a PTA-Hageman factor interaction.

Nonspecific one-stage plasma clotting tests. See PCa, PT and PTT under Foreword and under Methods. Table III presents results of these three routine and special tests on a single batch of normal fresh citrated human plasma. Each test used $0.1 \mathrm{ml}$ plasma; $0.1 \mathrm{ml}$ of the combined special additives [containing $5 \mu \mathrm{g}$ Tryp. A, and 1:50 dilution (VII $+\mathrm{X}$ ), where indicated]. The "combination," in Tests 4 , was preincubated (see below) for 1 minute at $37^{\circ} \mathrm{C}$ before adding the substrate plasma and the routine activators. The data of Table III show a small, but significant, clotaccelerating action of the $5 \mu \mathrm{g}$ of trypsin (Tests 2 ) in all three tests. The very minor effects of the $(\mathrm{VII}+\mathrm{X})$, in Test 3 , could be due to the trace of prothrombin noted under Methods. The "combination," Test 4, however, evinced a dramatic "synergism," which represents a new and very interesting phenomenon. It is probably significant that the synergized clotting times remain longest in the PCa test, that is, in the absence of added cephalin or tissue thromboplastin. With the combined additives, the cephalin (PTT) test gave values of the order usually encountered with tissue thromboplastin (PT) tests. The PT test, however, could be boosted to super-normal values.
TABLE IV

Trypsin, $(V I I+X)$, and a "combination," in specific one-stage tests for $V(A c G), I I($ Pro $T)$, and $(V I I+X)$, after Owren (15)*

\begin{tabular}{|c|c|c|c|c|c|}
\hline Test & Additives & $\mathrm{V}(\mathrm{AcG})$ & II (Pro T) & \multicolumn{2}{|c|}{$(\mathrm{VII}+\mathrm{X}):$ Units } \\
\hline 1 & o (B. sal.) & 87.5 & 104.5 & 145.1 & $\mathbf{0}$ \\
\hline 2 & Tryp. A, $2 \mu \mathrm{g}$ & 90.3 & 108.5 & 91.8 & 4 \\
\hline $\begin{array}{l}3 \\
4\end{array}$ & $\begin{array}{l}\text { (VII + X) } 1: 50 \\
\text { Tryp. A + (VII + X) }\end{array}$ & $\begin{array}{l}88.7 \\
75.4\end{array}$ & $\begin{array}{l}73.2 \\
78.3\end{array}$ & $\begin{array}{l}30.3 \\
13.2\end{array}$ & $\begin{array}{r}20 \\
200\end{array}$ \\
\hline & 1 ryp. $A+(V 11+x)$ & 75.4 & 18.3 & & \\
\hline
\end{tabular}

* Clotting times in seconds, at $37^{\circ} \mathrm{C}$. Units (last column) as de scribed in text.

Specific one-stage clotting tests (see Foreword). Table IV shows typical results in testing (3) for $\mathrm{V}(\mathrm{AcG}), \mathrm{II}$ (ProT), and (VII $+\mathrm{X})$, the last by the Owren (15) method. Appropriate deficient plasma substrates (see Methods) were used with the routine Ca-thromboplastin activation, and special $0.1 \mathrm{ml}$ additions of trypsin (Test 2), (VII $+\mathrm{X})$ as above (Tests 3 ), and the combination (Test 4). The same 1:50 dilution of (VII $+\mathrm{X}$ ) was used as in the Table III tests, but the trypsin (Tryp. A) was reduced to $2 \mu \mathrm{g}$, with a preincubation period (see below) of 3 minutes. There were no significant effects of the trypsin, in Test 2. The 20 unit (VII $+\mathrm{X}$ ), in Test 3 , was inconsequential in the other assays, i.e., nil in $\mathrm{V}$, and merely suggestive, in II, of the trace of contaminating prothrombin. The combination, in Test 4 , was also ineffectual in the $\mathrm{V}(\mathrm{AcG})$ and II (ProT) tests. In the Owren (VII $+\mathrm{X}$ ) test, however, it reproduced the same synergistic phenomenon as that previously found in the nonspecific tests (Table III). In the last column are given the percentage assay values, which show a tenfold increase in unitage (Test 4 vs Test 3 ) when the trypsin reacts with the (VIl $+\mathrm{X})$. For these assays, the same preparation of (VII + $\mathrm{X})$ was used as the standard, a 1:10 dilution being designated 100 per cent and a series of dilutions tested to provide data for a curve of reference. The actual test data are reproduced in Table V.

Effects of preincubation of trypsin with (VII +

TABLE V

$(V I I+X)$ dilutions tested for use as reference standard in connection with $(V I I+X)$ tests of Table IV *

\begin{tabular}{cccccccccccc}
\hline \hline Units....... & 200 & 100 & 75 & 50 & 30 & 20 & 10 & 5 & 1 & 0 \\
\hline Clotting time & 13.2 & 14.2 & 15.6 & 17.7 & 21.7 & 30.3 & 54.1 & 88.5 & 123.2 & 145.1
\end{tabular}

* Clotting times in seconds, at $37^{\circ} \mathrm{C}$. Units as percentages $(100=1: 10$ dilution $)$. 
TABLE VI

Preincubation of trypsin with $(V I I+X)$, tested by the Owren one-stage (as in Table IV)

\begin{tabular}{lccccc}
\hline \hline & & & & \\
Preincub. time (min) $\ldots$ & 0.5 & 1 & 2 & 3 & 5 \\
Clotting time (sec) $\ldots$ & $\ldots 8.7$ & 16.6 & 15.5 & 13.2 & 13.9 \\
Units (from Table V) & 44 & 60 & 77 & 200 & 130 \\
\hline
\end{tabular}

X) received preliminary study, in order to determine suitable concentrations of trypsin and optimal incubation periods. Table VI cites these data for the particular agents used in the experiments of Table IV. There is clearly an optimal incubation period of about 3 minutes and important evidence, in the last test, of instability of the synergistic activity beyond the optimum. The optimal preincubation period, in a series of such studies, seemed to be independent of the (VII + $\mathrm{X}$ ) dilution, but varied with the trypsin concentration. With $5 \mu \mathrm{g}$ trypsin (as in Table III) 1 minute was sufficient, and higher enzyme strengths required only a few seconds.

Special one-stage tests, on plasmas specifically deficient in factor $\mathrm{X}$ or in factor VII, are included in Table VII. The first four experiments were preliminary data secured with crude trypsin (Tryp. C). Tests 5 through 10 , with crystalline trypsin, were performed many months later, with the same preparation (Case L.B.) of VII-deficient plasma (frozen-stored), but with another case (A.G.) with X-deficiency. Reagent $X$ (Stuart) was purified (rerun) by continuous flow paper curtain (Spinco) electrophoresis (28), and contained no VII or other detectable clotting factor than $\mathrm{X}$. Its specific potency was tested on plasmas from Case A.G. and from the original R.S. (Stuart), which was used in the first test series. Reagent $V I I+X, 1: 50$, was the same

TABLE VII

Special one-stage tests on $X$ - and VII-plasmas, adding trypsin, diluted Stuart $(X)$ and $(V I I+X)$ preparations *

\begin{tabular}{|c|c|c|c|c|c|}
\hline Test & Additives & $\mathrm{X}-$ & Units & VII- & Units \\
\hline $\begin{array}{l}1 \\
2 \\
3 \\
4\end{array}$ & $\begin{array}{l}0 \text { (B. sal.) } \\
\text { Tryp. }{ }_{X}^{X}(200 \mu g) \\
\text { Tryp. } C+X\end{array}$ & $\begin{array}{l}41.3 \\
38.8 \\
21.9 \\
18.8\end{array}$ & $\begin{array}{r}3 \\
4 \\
50 \\
80\end{array}$ & $\begin{array}{l}75.8 \\
61.3 \\
60.1 \\
60.0\end{array}$ & $\begin{array}{l}<1 \\
<1 \\
<1\end{array}$ \\
\hline $\begin{array}{r}5 \\
6 \\
7 \\
8 \\
9 \\
10\end{array}$ & $\begin{array}{l}\text { 0 (B. sal.) } \\
\text { Tryp. A }(5 \mu \mathrm{g}) \\
\text { X } \\
\text { Tryp. A X } \\
\text { (VII +X) 1:50 } \\
\text { Tryp. A + (VII + X) }\end{array}$ & $\begin{array}{l}62.1 \\
49.8 \\
26.7 \\
22.0 \\
33.5 \\
12.1\end{array}$ & $\begin{array}{r}0 \\
<1 \\
24 \\
48 \\
9 \\
>200\end{array}$ & $\begin{array}{l}46.5 \\
36.5 \\
43.5 \\
32.5 \\
27.7 \\
16.9\end{array}$ & $\begin{array}{r}1 \\
5 \\
2 \\
8 \\
14 \\
65\end{array}$ \\
\hline
\end{tabular}

* Clotting times in seconds, at $37^{\circ} \mathrm{C}$. Units from standard reference curves.
TABLE VIII

PTT tests on Hag-, AHF (VIII)-, and PTC (IX)-plasmas *

\begin{tabular}{llrcc}
\hline \hline Test & \multicolumn{1}{c}{ Additives } & Hag- & AHF(VIII)- & PTC(IX)- \\
\hline 1 & 0 (B. sal.) & 317.6 & 207.8 & 800 \\
2 & 20 $\mu$ Tryp. A & 38.1 & 28.2 & 50 \\
3 & 2 Mg Tryp. A & 227.3 & 82.6 & 336 \\
4 & 1:50 (VII + X) & 226.9 & 171.5 & 518 \\
5 & $2 \mu \mathrm{g}$ Tryp. A + (VII + X) & 14.9 & 8.7 & 9.7 \\
6 & Hag & 47.8 & & \\
7 & Hag + Tryp. A, 2 $\mu \mathrm{g}$ & 47.9 & & \\
& & & & \\
\hline
\end{tabular}

* Effects of trypsin, (VII + X), and a "combination." Hag preparation also tested, with and without trypsin, in the Hag- test series. Clotting times in seconds, at $37^{\circ} \mathrm{C}$.

as that used in preceding experiments. The results show: a) no significant effects of the trypsins alone, in Tests 2 and $6 ; b$ ) good correction of the X-, but not the VII-, tests by the purposely diluted Stuart $(\mathrm{X})$ reagent in Tests 3 and $7 ; c$ ) a definite synergism in Tests 4 and 8 , on the X-, but not on the VII-, substrate. In the former, factor VII is present in the substrate and factor $\mathrm{X}$ is added; in the latter, the factor VII deficiency remains. When (VII $+\mathrm{X})$, purposely weak, is substituted for the $\mathrm{X}$-reagent, giving the small corrections seen in Test 9 , there is a very marked synergism with trypsin, Test 10 , in the case of both substrates.

One-stage PTT tests on Hag-, AHF (VIII)-, and PTC (IX)-plasmas (see Foreword). Substrates were obtained from well studied cases. Table VIII shows results of these specific tests upon the addition of : a) crystalline trypsin (Tryp. A) in $20 \mu \mathrm{g}$ (Test 2) or $2 \mu \mathrm{g}$ (Test 3) amounts; $b)(V I I+X) 1: 50$ (Test 4$)$; or a combination of the last with $2 \mu \mathrm{g}$ Tryp. A (preincubated for 3 minutes) in Test 5 . The results show that the clot acceleration in all three tests by $20 \mu \mathrm{g}$ per $\mathrm{ml}$ trypsin was reduced to slight significance at the level of $2 \mu \mathrm{g}$ trypsin. The $1: 50$ $(\mathrm{VII}+\mathrm{X})$ also had extremely minor effects. But in the combination, Test 5 , there was again a most dramatic synergism with all three substrates. These, obviously, are not specific corrections.

In other Hag- tests: a $\mathrm{Hag}^{2}$ preparation gave good correction, alone (Test 6 ), and this was unaffected by combining it with $2 \mu \mathrm{g}$ of crystalline trypsin (Test 7). The $\mathrm{Hag}^{2}$ preparation was obtained by fractionation of recalcified human bank blood (outdated) according to Ratnoff's procedure (25).

\footnotetext{
2 See Table VIII, Tests 6 and 7.
} 
TABLE IX

Eluate two-stage tests: effects of trypsin, with various specific factor deficiencies $\left(25^{\circ} \pm 1^{\circ}\right.$ C)

\begin{tabular}{|c|c|c|c|c|c|}
\hline \multirow[b]{2}{*}{ Test } & \multirow[b]{2}{*}{ Trypsin } & \multirow[b]{2}{*}{ Defic. } & \multicolumn{3}{|c|}{ Incubation period } \\
\hline & & & $0.5 \mathrm{~min}$ & Opt. (m & \\
\hline & & & $\mathrm{sec}$ & $\mathrm{sec}$ & $\min$ \\
\hline \multirow[t]{2}{*}{1} & - & 0 & 240 & 23.2 & 6 \\
\hline & + & 0 & 41.7 & 23.5 & 3 \\
\hline \multirow[t]{2}{*}{2} & - & $\mathrm{Ca}$ & $\infty$ & $\infty$ in & \\
\hline & + & $\mathrm{Ca}$ & $\infty$ & $\infty$ in & \\
\hline \multirow[t]{2}{*}{3} & - & Ceph. & $\infty$ & $690 \mathrm{in}$ & 30 \\
\hline & + & Ceph. & 1,010 & $194 \mathrm{in}$ & 30 \\
\hline \multirow[t]{2}{*}{4} & - & $\mathrm{V}$ & 600 & 30.6 & 30 \\
\hline & + & V & 610 & 102. & 18 \\
\hline \multirow[t]{2}{*}{5} & - & VII & 345 & 70.5 & 10 \\
\hline & + & VII & 330 & 76.8 & 14 \\
\hline \multirow[t]{2}{*}{6} & - & $\mathrm{X}$ & 210 & 35.4 & 7 \\
\hline & + & $\bar{X}$ & 230 & 37.4 & 10 \\
\hline \multirow[t]{2}{*}{7} & - & Hag & 195 & 34 & 7 \\
\hline & + & $\mathrm{Hag}$ & 87.8 & 30.3 & 4 \\
\hline \multirow[t]{2}{*}{8} & - & VIII & 480 & 38.4 & 9 \\
\hline & + & VIII & 88.9 & 33.2 & 5 \\
\hline \multirow[t]{2}{*}{9} & - & IX & 210 & 55.7 & 7 \\
\hline & + & IX & 92 & 49.9 & 5 \\
\hline
\end{tabular}

Two-stage tests. The principles of these have been reviewed in the Foreword. Technical details are omitted, since these are available in cited references $(1,4,23)$. Here we merely omit $(-)$ or add $(+)$ trypsin in the thrombin-forming incubate, which is composed of eluates (containing prothrombin and so forth) and additives. From the standard $(5 \mathrm{ml})$ volume of incubate at room temperature (averaging $26^{\circ} \mathrm{C}$ ), $0.2 \mathrm{ml}$ samples are added at successive intervals to $0.2 \mathrm{ml}$ fibrinogen and the clotting time noted. The 0.5 minute and endpoint (optimal) times are given in Tables IX and $\mathrm{X}$, and inspection of the data readily reveals any significant action of the trypsin.

Various factor deficiencies, with and without added trypsin, were tested by the eluate twostage, with the results summarized in Table IX. Crude tryp. C, $200 \mu \mathrm{g}$ per $5 \mathrm{ml}$ incubate, was used throughout in these early (1959) experiments, and the factor deficiencies were $a$ ) artificial (i.e., omitting the routine additive) in Tests 2 ( $\mathrm{Ca}-), 3$ (Ceph-) and $4(\mathrm{~V}-)$; and $b$ ) clinical cases, in Tests 5 (VII-; L.B.), ${ }^{3} 6$ (X-; A.G.), 7 (Hag-; L.C.), 8 (VIII-) and 9 (IX-). Tissue thromboplastin was used in Test $5 .^{3}$ All others were cephalin-activated.

Test 1 , with a normal (0 deficient) system, showed a much shorter 0.5 minute test and only one-half the optimal incubation period with trypsin, as compared with the control; the endpoints were the same, however. Thus, trypsin does not make more thrombin, but merely speeds up the activation. In Test 2 (Ca-), no detectable thrombin formed, with or without trypsin, at least in 30 minutes. The action of trypsin requires $\mathrm{Ca}^{++}$. In Test 3 (Ceph-), there was again virtually no thrombin formation, indicating need for the prothromboplastic lipid. In Test $4(\mathrm{~V}-)$, the eluate was heated to $52^{\circ} \mathrm{C}$ for 30 minutes and the AcG addition omitted. An exceedingly small trace of AcG suffices for some thrombin formation, and an absolute V-deficiency is not easily obtained (29). Nevertheless, the activation here was all but negligible and trypsin, if anything, made it worse (esspecially the endpoint), perhaps destroying some of the residual traces of AcG. Specifically separate VII- and X-deficiencies were present in Tests $5^{3}$ and 6 , respectively. In each case, trypsin failed to improve the inadequate thrombin formation. Trypsin, therefore, needs both of these factors also. In Test 7 (Hag-), 8 (AHF-) and 9 (PTC-), there was a different pattern of results, returning to that found in Test 1 (nondeficient). Thus, when trypsin was added, thrombin forma-

3 See Table IX.

TABLE $\mathrm{X}$

Two-stage tests on eluates (see text) from Normal, X- (Mr. Stuart), and VII- (L.B.): effects of adding trypsin, $(V I I+X)$, or a "combination" *

\begin{tabular}{|c|c|c|c|c|c|c|c|c|c|c|}
\hline \multirow[b]{2}{*}{ Test } & \multirow[b]{2}{*}{ Additives } & \multicolumn{3}{|c|}{ Normal } & \multicolumn{3}{|c|}{$\mathrm{X}$-(Stuart) } & \multicolumn{3}{|c|}{ VII-(L.B.) } \\
\hline & & $0.5 \mathrm{~min}$ & Opt. & & $0.5 \mathrm{~min}$ & Opt. & & $0.5 \mathrm{~min}$ & Opt. & \\
\hline & & $\sec$ & $\sec$ & $\min$ & $\sec$ & $\sec$ & $\min$ & $\sec$ & $\sec$ & $\min$ \\
\hline 1 & 0 & 271.5 & 24.9 & 10 & 267.2 & 27.8 & 22 & 345 & 70.5 & 10 \\
\hline 2 & Trypsin & 187.4 & 24.0 & 7 & 171.1 & 31.5 & 30 & 330 & 76.8 & 14 \\
\hline 3 & $(\mathrm{VII}+\mathrm{X})$ & 158.9 & 25.7 & 8 & 129.6 & 25.8 & 10 & 180 & 26.0 & 7 \\
\hline 4 & Tryp. A + (VII + X) & 30.3 & 20.0 & 2 & 34.4 & 22.2 & 3 & 102.4 & 21.1 & 8 \\
\hline
\end{tabular}

* Clotting times in seconds, after incubation periods of 0.5 minute and at the optimum, in minutes, at $25^{\circ} \mathrm{C}$. 
tion was distinctly accelerated and improved, despite the specific deficiencies, respectively, in Hag, VIII, or IX. Hence trypsin does not need these three factors for its action in assisting thrombin formation. While we have not yet had the opportunity to study PTA specificially, there are some indications that this also will turn out to be nonessential for the clot-aiding action of trypsin.

Special two-stage tests. Table $\mathrm{X}$ gives results on the effects of adding trypsin, (VII $+\mathrm{X}$ ), or a combination, to activated eluates: $a$ ) Normal, b) X- (Mr. Stuart), c) VII- (L.B.). In each case, $0.1 \mathrm{ml}$ of $1: 5$ dilution of the corresponding fresh supernate, after the $\mathrm{BaSO}_{4}$ adsorption of the plasma, was added to provide $\mathrm{AcG}, \mathrm{AHF}$, PTA, Hageman, and the AcG(V) was further boosted by $0.1 \mathrm{ml}$ of a $1: 10$ dilution of $\mathrm{BaCO}_{3}$ adsorbed beef serum. One-tenth $\mathrm{ml}$ of eluate was used in all tests. The $(\mathrm{VII}+\mathrm{X})$ was $0.1 \mathrm{ml}$ of a $1: 10$ dilution in each case, but the $0.1 \mathrm{ml}$ trypsin differed, viz., a) $5 \mu \mathrm{g}$ Tryp. B ; $b) 20 \mu \mathrm{g}$ Tryp. A, c) $200 \mu \mathrm{g}$ Tryp. C. One -tenth $\mathrm{ml}$ tissue thromboplastin in $c$ ), ${ }^{4}$ or ceph. (human brain cephalin, 0.15 per cent) in $a$ ) and $b$ ), and $0.5 \mathrm{ml} \mathrm{Ca}(0.15 \mathrm{M}$ $\mathrm{CaCl}_{2}$ ) were the routine activators, and all incubates were made up to $5 \mathrm{ml}$ with $\mathrm{b}$. sal.

The major findings were: 1) trypsin, alone, in the Normal significantly improved the rate of thrombin formation, as shown by the initially $(0.5$ minute) shorter clotting-time and by the reduction in the optimal incubation period needed, whereas, the enzyme failed significantly to improve the activations in the X-and VII- incubates. 2) Trypsin, with $(\mathrm{VII}+\mathrm{X})$, markedly improved the activa-

4 See Table X. tions in Test 4 , in which the special additives were preincubated for 1 minute before adding the other components. Minor technical imperfections are apparent in these tests, but do not detract from the significant major conclusion, confirmatory of the results with the one-stage tests, that trypsin acts synergistically with both VII and X.

Lack of influence of trypsin on the fate of factor VII activity in shed Stuart $(X-)$ blood. The Quick (PT) test (12), Owren's (VII $+\mathrm{X}$ ) test (15), or specific one-stage factor VII assays (30) show a remarkable phenomenon concerning the changes of factor VII activity in shed normal blood. Activity values up to 200 to 300 per cent of the original plasma level are frequently encountered after withdrawing the blood sample and allowing it to clot (in glass) at $37^{\circ} \mathrm{C}$. Factor $\mathrm{X}$ behaves quite differently, showing only minor fluctuations essentially indicating no change from the original plasma level (30). In VII- or X-cases, the respective missing factor would not be expected to arise in the serum de novo, and data are available to confirm this. There is also no reason to expect the fate of $\mathrm{X}$ to be different in VII-deficient blood, and this, too, can be substantiated. It is of interest to follow the fate of VII activity in X-deficient blood. A rare opportunity to do this occurred recently during a visit of the original $\mathrm{Mr}$. Stuart (X-). Specific one-stage factor VII assays were performed, thanks to availability of plasma substrate from Case L.B. (VII-). The Owren test (for VII $+\mathrm{X}$ ) was also run, but gave very low values throughout, merely indicating that no change occurred which might counteract the deficiency of factor $\mathrm{X}$, which is also needed for this test. Four tubes of blood were incubated with

TABLE XI

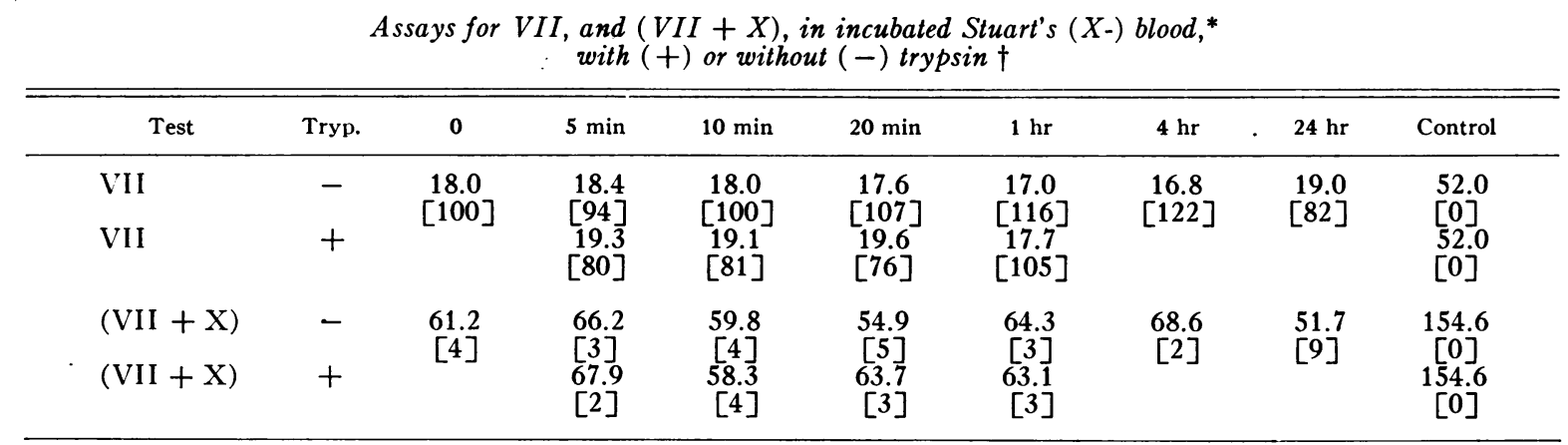

* Clotting time $\left(37^{\circ} \mathrm{C}\right)$ : with $20 \mu \mathrm{g} / \mathrm{ml}$ trypsin, 16 minutes; without trypsin, 19 minutes.

$\dagger$ Clotting times in seconds; percentage units in brackets; temperature $37^{\circ} \mathrm{C}$. 
$1 / 10$ volume crystalline trypsin, tryp. A, to 20 $\mu \mathrm{g}$ per $\mathrm{ml}$, the others receiving an equivalent volume of $b$. sal. Unitages were computed from standard curves with normal human plasma dilutions. The data are given in Table XI. The results show only very minor changes in VII-activity over 24 hours, in the absence of trypsin. This is quite unlike the normal post-clotting rise in VII activity (30). With trypsin followed over 1 hour, the results were not significantly influenced.

This single experiment must be regarded as preliminary, and it is hoped that we, and others, will find similar opportunities for its future repetition and further analysis. Such has perhaps appeared recently in a report by Hougie (31). One of his cases (A.G.) showed results similar to the above, whereas another (identified as "mild," with perhaps some 10 per cent of the normal X) behaved normally.

\section{DISCUSSION}

Using microgram amounts of trypsin largely avoids known (1) destructive actions of the enzyme on clotting proteins and brings out some remarkable clot-accelerating effects in a variety of test systems. By the failure of these to occur in factor-deficient systems, it is clear that the action of trypsin requires $\mathrm{Ca}$-ions, a special pro-thromboplastic (4) lipid, such as cephalin, together with factors V, VII, and X, but not factors VIII, IX, (PTA), or Hageman. While this is still a complex thrombin-forming system, involving at least seven components, when prothrombin and trypsin are included, it is, nevertheless, somewhat simpler than the natural plasma system, which requires at least four more factors, namely, Hageman, PTA, PTC(IX), and AHF(VIII). We have previously presented an experimental analysis (4) of the mode of action of Russell's viper venom (Stypven), which differs from trypsin in not requiring factor VII. Later papers of the present research will deal with other enzymes and so forth and add further data to strengthen the current body of facts which point to a diversity of possible thromboplastin- and thrombin-forming systems.

Incidentally, plasmin and other thrombolytic agents do not act in these ways, but merely contribute a Hageman-like effect to explain their ability to accelerate blood-clotting (10). Plasmin is not a "thromboplastic enzyme."
It will be a long time before the complex multicomponent reactions of blood-clotting permit a genuinely biochemical interpretation. In the meantime, it seems helpful to regard trypsin (and certain other enzymes) as accessory factors in their own right. They work with particular groups of the natural cofactors, and diverse combinations of accessory factors (according to the enzyme) achieve the same end result, namely, thrombin formation. It is premature to speculate what the intermediary pathways may be.

In 1916, Dale and Walpole (32) reported that trypsin "liberated an active thrombokinase" in fowl plasma. Our past work (1) emphasizes key roles for calcium ions and a special lipid (or lipids) which we propose to call "prothromboplastic phosphatide" (4). The term "thromboplastic enzyme" ( 7$)$, based on experiments with trypsin, indicates catalysis of the "thromboplastin" [if such there be (4)] and thrombin-forming reactions. The new discovery (26) of the remarkable synergistic reaction between trypsin and both factors VII and X, may very well be of the most fundamental significance. May it not, for instance, suggest that very small amounts of these accessory factors suffice in the presence of trypsin? Does the effectiveness of trypsin in activating highly purified prothrombins depend upon trace impurities of these cofactors which, perhaps, cannot be detected in any other way? Our previous work with at least one purified prothrombin did not reveal any thrombin-forming activity of trypsin alone or with calcium, but only when (weak) thromboplastin was added (23). Another of our Seegerstype prothrombins, at that time (1947), showed complete activation spontaneously in several months at ice-box temperatures. We could only suggest the presence in this of significant trace contaminants of all essential activators (1). In our "complete," or single-factor deficient, present two-stage systems, micrograms of trypsin reveal their effectiveness (or lack of it) in a very few minutes. We make no claims whatever for other than relative factor inadequacies in the current reagents. Hence results of using stronger enzymes and hours of incubation (24) are regarded as another story, in which we would personally raise cogent questions as to possible trace contaminants. Additional complications with larger 
amounts of enzyme undoubtedly include destructions of certain clotting factors, perhaps even of thrombin itself (24). The lower and upper limits of effectiveness of each individual clotting factor need to be worked out for each variant of the clotting test system. The permutations and combinations are almost endless, and offer a fruitful field for further enquiry and possible practical applications.

We have tried, without significant results, to combine trypsin with other accessory factors, which are at present available to us only in crude forms. For instance, preliminary two-stage tests employing trypsin with normal $\mathrm{BaSO}_{4}$-adsorbed plasma to restore $\mathrm{AHF}$, or with serum to restore PTC, at first suggested some potentiation, compared with trypsin alone. This led to an error on page 160 of our monograph (1) in which VIII and IX were included among the cofactors needed by trypsin. Rechecking the data revealed that these findings were caused by traces of prothrombin in the added plasma or serum preparations. Factors VIII and IX are not needed and correction of the error is herewith requested.

The argument that trypsin can help reveal traces of factors VII and $\mathrm{X}$ can be reversed. Is it not possible that the normal increase in VII activity in shed blood could be due to the working of a natural "tryptase" (i.e., trypsin-like, in a broad sense) enzyme in the blood? Our single experiment, on the fate of VII activity in X-blood, needs confirmation and an attempt should be made to restore the normal post-clotting rise in VII activity, simply by adding factor $\mathrm{X}$. On all these matters our ideas are very tentative. We do feel, however, that present indications encourage further exploration of a "thromboplastic enzyme" theory of blood clotting (33).

\section{SUM MARY}

Trypsin accelerates blood clotting in a variety of test systems. This requires $\mathrm{Ca}$-ions, cephalin (or equivalent prothromboplastic lipid), together with accessory factors $\mathrm{V}, \mathrm{VII}$, and $\mathrm{X}$, but not VIII, IX, (PTA), or Hageman. In combination with both VII and X, trypsin acts with a powerful synergism. The further exploration of what lies behind these experimental facts could lead to the establishment of a "thromboplastic enzyme" theory of blood clotting.

\section{REFERENCES}

1. Ferguson, J. H. Lipoids and Blood Platelets, with Reference to Blood Coagulation and the Hemorrhagic Diseases. Chapel Hill, Univ. N. Carolina Press, 1960, p. 278.

2. Wright, I. S. Nomenclature of blood clotting factors. Thromb. Diath. haemor. 1959, 3, 435.

3. Lewis, J. H., Ferguson, J. H., Fresh, J. W., and Zucker, M. B. Primary hemorrhagic diseases. J. Lab. clin. Med. 1957, 49, 211.

4. Ferguson, J. H. Methods of studying new clotting factors in New Blood Clotting Factors (Montreux Conf. Proc.) Thromb. Diath. haemor. 1960, 4, suppl. p. 226.

5. Douglas, S. R., and Colebrook, L. On the advantage of using a broth containing trypsin in making blood cultures. Lancet 1916, 2, 180.

6. Eagle, H., and Harris, T. N. Studies in blood coagulation. V. The coagulation of blood by proteolytic enzymes (trypsin, papain). J. gen. Physiol. 1937, $20,543$.

7. Ferguson, J. H., and Erickson, B. N. The coagulant action of crystalline trypsin, cephalin and lung extracts. Amer. J. Physiol. 1939, 126, 661.

8. Soulier, J. P., and Larrieu, M. J. Déficit en 3ème facteur prothromboplastique plasmatique. Rapports entre le PTA et la facteur Hageman. Thromb. Diath. haemor. 1958, 2, 1.

9. Margolis, J. The role of Hageman factor in plasma/ surface reactions in Hemophilia and Other Hemorrhagic States. Internat. Symp., Rome, K. M. Brinkhous and P. de Nicola, Eds. Chapel Hill, Univ. N. Carolina Press, 1959, p. 208.

10. Iatridis, S. G., Wilson, E. G., Ferguson, J. H., and Rierson, H. A. Blood clotting activities of thrombolytic agents, with special reference to a Hagemanlike effect. Thromb. Diath. haemor. In press.

11. Waaler, B. A. Contact activation in the intrinsic blood clotting system. Scand. J. clin. Lab. Invest. 1959, 11, Suppl. 37.

12. Quick, A. J., Stanley-Brown, M., and Bancroft, F. W. A study of the coagulation defect in hemophilia and in jaundice. Amer. J. med. Sci. 1935, 190, 501.

13. Langdell, R. D., Wagner, R. H., and Brinkhous, K. M. Effect of antihemophilic factor on one-stage clotting tests. A presumptive test for hemophilia and a simple one-stage antihemophilic factor assay procedure. J. Lab. clin. Med. 1953, 41, 637.

14. Bell, W. N., and Alton, H. A. A brain extract as a substitute for platelet suspensions in the thromboplastin generation test. Nature (Lond.) 1954, 174, 880.

15. Owren, P. A. Prothrombin and accessory factors. Amer. J. Med. 1953, 14, 201. 
16. Ferguson, J. H., Lewis, J. H., and Arends, T. Hemorrhagic disease with circulating inhibitors of blood clotting anti-AHF and anti-PTC in eight cases. Blood 1956, 11, 846.

17. Ferguson, J. H., Johnston, C. L., Jr., and Howell, D. A. A circulating inhibitor (anti-AcG) specific for the labile factor $\mathrm{V}$ of the blood-clotting mechanism. Blood 1958, 13, 382.

18. Ferguson, J. H. A standardized procedure for the study of coagulation reactions (in vitro). J. Lab. clin. Med. 1938, 24, 273.

19. Ware, A. G., and Seegers, W. H. Two-stage procedure for the quantitative determination of prothrombin concentration. Amer. J. clin. Path. 1949, 19, 471.

20. Smith, H. P., Warner, E. D., and Brinkhous, K. M. Prothrombin deficiency and the bleeding tendency in liver injury (chloroform intoxication). J. exp. Med. 1937, 66, 801.

21. Ware, A. G., and Seegers, W. H. Plasma accelerator globulin: Partial purification, quantitative determination, and properties. J. biol. Chem. 1948, 172, 699.

22. Seegers, W. H., McClaughry, R. I., and Fahey, J. L. Some properties of purified prothrombin and its activation with sodium citrate. Blood 1950, 5, 421.

23. Ferguson, J. H., Travis, B. L., and Gerheim, E. B. The activation of prothrombin, with special reference to "thromboplastic enzyme" (tryptase). Blood 1948, 3, 1130.

24. Alexander, B. Some biochemical, physicochemical and immunochemical studies of prothrombin and proconvertin (Factor VII): Their biopathologic significance in Fourth Internat. Congr. Biochem., Symp. no. 10, Blood Clotting Factors, E. Deutsch, Ed. London, Pergamon Press, 1958, p. 37.

25. Johnston, C. L., Jr., Ferguson, J. H., and O'Hanlon, F. A. Surface activation of plasma clotting: A function of Hageman factor. Proc. Soc. exp. Biol. (N. Y.) 1958, 99, 197.

26. Pechet, L., and Alexander, B. Activation of prothrombin, factors VII and $\mathrm{X}$ by proteolytic pathway. Fed. Proc. 1960, 19, 64.

27. Lewis, J. H., and Ferguson, J. H. Partial purification of human prothrombin and proconvertin: Their characteristics and interaction. J. clin. Invest. 1953, 32, 915.

28. Johnston, C. L., Jr., Ferguson, J. H., O'Hanlon, F. A., and Payne, R. B. Isolation of coagulation factors by continuous flow electrophoresis. Proc. Soc. exp. Biol. (N. Y.) 1959, 101, 747.

29. Lewis, J. H., and Ferguson, J. H. Thrombin formation. I. The role of calcium, serum Ac-globulin and tissue thromboplastin. J. clin. Invest. 1948, 27, 778.

30. Johnston, C. L., Jr., Ferguson, J. H., O'Hanlon, F. A., and Black, W. L. The fate of Factor VII and Stuart factor during the clotting of normal blood. Thromb. Diath. haemor. 1959, 3, 367.

31. Hougie, C. Studies on the fate of coagulation factors during the clotting of normal and pathological blood. Thromb. Diath. haemor. 1959, 3, 578.

32, Dale, H. H., and Walpole, G. S. Some experiments on factors concerned in the formation of thrombin. Biochem. J. 1916, 10, 331.

33. Ferguson, J. H. A new blood-clotting theory. Science 1943, 97, 319. 